\title{
Girişimcinin Finansmanında Alternatif Bir Yöntem: Kitlesel Fonlama*
}

\section{ÖZET}

Girişimcilerin, özellikle yeni ve küçük girişimcilerin, projelerini finanse etmek için ihtiyaç duydukları fonu bulmaları hem gelişmiş ülkelerde hem de gelişmekte olan ülkelerde önemli bir sorun olmaya devam etmektedir. Son yıllarda, kitlesel fonlama, girişimcilerin projelerini hayata geçirmelerine velveya işletmelerini finanse etmelerine imkân veren alternatif bir yöntem olarak ortaya çıkmıştır. Kitlesel fonlamada, fon arayan girişimciler, kitlesel fonlama platformlarını ve sosyal medyayı kullanarak çok sayıdaki kişiden (kitlelerden) fon talebinde bulunmaktadırlar. Fon sağlayanlar ise, herhangi bir karşıllı beklemeden (bağış bazlı) ya da finansal olmayan (ödül bazlı) veya finansal (borç bazlı ve pay bazlı) bir ödül/getiri karşılığında girişimcilerin projelerine destek olmaktadırlar. Bu çalışmanın amacı, fon bulmak amacıyla kitlesel fonlamayı kullanmayı düşünen veya nereden fon bulabilirim sorusuna yanıt arayan girişimcilere kitlesel fonlama hakkında genel bir çerçeve sunmaktır. Bu kapsamda nitel araştırma yöntemi kullanılmıştır. Girişimcilerin nispeten yeni bir finansman yöntemi olan kitlesel fonlamaya ilgi ve taleplerinin giderek artacağ ve düzenleyici kurumların bu piyasaya yönelik yapacakları düzenlemelerin de piyasanın gelişimini ve büyümesini teşvik edeceği değerlendirilmektedir.

Anahtar Kelimeler: Girişimci, Girişimcinin Finansmanı, Kitlesel Fonlama

JEL Sinıflandırması: G20, L26, M13.

\section{An Alternative Method in Entrepreneurial Financing: Crowdfunding}

\section{ABSTRACT}

The fact that entrepreneurs, especially new and small entrepreneurs, find the funding they need to finance their projects continues to be an important problem in both developed and developing countries. In recent years, crowdfunding has emerged as an alternative method that allows entrepreneurs to finance their projects and/or businesses. In crowdfunding, entrepreneurs seeking funds demand funds from a large number of people (crowds) using crowdfunding platforms and social media. Funders support entrepreneurs' projects in return a nonfinancial (reward-based) and financial (debt-based and equity-based) reward/return or without expecting any return (donation-based). This study aims to provide a general framework for crowdfunding to entrepreneurs who are considering crowdfunding to find funds or seeking answers to the question of where can I find funds. In this context, qualitative research method was used. It is considered that the interest and demands of the entrepreneurs to crowdfunding, which is a relatively new financing method, will gradually increase, and the regulations that the regulatory institutions will make will also encourage the development and growth of the market.

Keywords: Entrepreneur, Entrepreneurial Financing, Crowdfunding

Jel Classification: G20, L26, M13.

\footnotetext{
* Makale Gönderim Tarihi: 20.02.2020, Makale Kabul Tarihi: 15.03.2020, Makale Türü: Nitel Araştırma ** Doç.Dr., Bursa Uludağ Üniversitesi, İktisadi ve İdari Bilimler Fakültesi, aadem@uludag.edu.tr, Orcid ID: 0000-0001-8909-6851.
} 


\section{GİRIŞ}

Girişimciler, genellikle girişim sürecinin ilk aşamasında fon bulmada zorlanmaktadırlar. Özellikle genç ve yeni girişimciler, bir iş geçmişleri olmadığı veya sınırlı olduğu için bankalar gibi geleneksel finansal kurumlardan fon sağlamada zorluk çekmektedirler. Bazı girişimciler, ailelerinden ve arkadaşlarından fon sağlayabilse de çoğu durumda bu da etkili ve yeterli olmayabilmektedir. İnternetin ve sosyal medyanın gelişmesi, girişimcilere fon bulmak için farklı bir alternatif sunmaktadır. Girişimciler; melek yatırımcılar, risk sermayedarları veya bankalar gibi geleneksel fon kaynakları yerine, kitlelerden veya halktan finansal destek aramaya başlamışlardır (Song ve van Boeschoten, 2015: 1; Beier ve Wagner, 2016: 3584). Bu finansman yöntemine "kitlesel fonlama" denilmektedir.

Son yıllarda, kitlesel fonlama kâr amaçlı veya kâr amacı gütmeyen küçük ölçekli veya başlangıç aşamasındaki projeler için alternatif bir dış finansman kaynağı haline gelmiştir. Kitlesel fonlamanın 2000'li yılların ortasından itibaren geleneksel finansman yöntemlerine bir alternatif olarak ortaya çıkmasının ve bu piyasanın hızla büyümesinin iki temel nedeni bulunaktadır. Birincisi, girişimcilerin fona ulaşmalarının önündeki engeller ve sınırlamalardır. Yeni bir iş kurmak isteyen girişimcilerin bankalardan kredi almaları kolay değildir. Aynı zamanda, bazı girişimciler de bankalardan yüksek maliyetle borç almak istemeyebilirler. Küçük girişimcilerin melek yatırımcılara ve risk sermayesi şirketlerine ulaşmaları, projelerini anlatmaları ve onları ikna ederek projelerine ortak olmalarını sağlamaları da çok kolay değildir. Özellikle 2008 yılında başlayan Küresel Ekonomik Kriz, küçük girişimciler için borç finansmanını önemli ölçüde azaltmış ve girişim sermayesi yatııımları da 2000-2009 yılları arasında \%82'nin üzerinde azalmıştır (Beaulieu vd., 2015:2). Geleneksel bankalar borç vermeye daha az istekli oldukları için, girişimciler başka yerlerde sermaye aramaya başlamışlardır (infoDev, 2013: 8). Kitlesel fonlama, finansal piyasalardaki bu boşluğu doldurmak üzere ortaya çıkmışıı. Kitlesel fonlamanın ortaya çıkmasının ve hızla gelişmesinin ikinci nedeni, internet başta olmak üzere iletişim teknolojilerinin gelişmesi ve kullanımının yaygınlaşmasıdır.

$\mathrm{Bu}$ çalışmanın amacı, girişimcilerin iş fikirlerini hayata geçirmelerine imkân veren ve yeni bir alternatif finansman yöntemi olarak ortaya çıkan kitlesel fonlama hakkında genel bir değerlendirme yaparak, girişimcilere bu yöntem hakkında farkındalık ve bilgi sağlamaktır. Potansiyel ve/veya mevcut girişimciler tarafindan kitlesel fonlamanın mantığının ve işleyişinin daha iyi anlaşılması, bu yöntemi kullanarak başarıı bir şekilde fon bulmalarına yardımcı olabilecektir. Çalışmanın amacına uygun olarak nitel araştırma yöntemi kullanılmıştır.

Nitel araştırma, ele alınan bir olay veya olgu hakkında gözlem, görüşme, doküman analizi gibi nitel veri toplama teknikleri kullanılarak yürütülen bilgi üretme süreci olarak ifade edilebilir (Baltac1, 2019: 370).

\section{KITTLESEL FONLAMANIN TANIMI}

Girişimcilik bağlamında kitlesel fonlama, "bireysel yatırımcıların veya grupların, kültürel, sosyal ve kâr amaçlı girişimlerini finanse etmek için, geleneksel finansal aracılar olmadan, interneti kullanarak çok sayıdaki bireyden küçük tutarlar şeklinde fon toplama 
çabası" olarak tanımlanabilir (Mollick, 2014: 2). Başlangıçta, kitlesel fonlama, web siteleri ve/veya çevrimiçi sosyal ağlar kullanılarak gerçekleştirilirken, web 2.0 teknolojilerinin ${ }^{1}$ gelişmesi ve kitle kaynak kullanımının başarısı, girişimcileri ve potansiyel fon sağlayanları bir araya getirerek bilgi akışını sağlayan ve işlemleri kolaylaştıran özel kitlesel fonlama platformlarının ortaya çıkmasına yol açmıştır. Kitlesel fonlama platformları, proje sahipleri ile potansiyel fon sağlayanları, web bazlı bir uygulama aracılığıyla bir araya getirmektedir (Zvilichovsky vd., 2015: 2).

Kitlesel fonlama platformları ortaya çıkmadan önce internet üzerinden sosyal ağlar ve web sitesi aracılığıyla yapılan kitlesel fonlamaya örnek olarak, 1997 yılında, İngiliz müzik grubu Marillion'un Amerika Birleşik Devletleri'ne (ABD) düzenleyeceği turne için ihtiyaç duyduğu 60.000 \$'1 internet üzerinden düzenlediği bir bağış kampanyasıyla destekçilerinden toplaması verilebilir. "Hotel Desire" filmi, kendi web sitesi aracılığıyla 80 günde $170.000 €$ toplamıştır (Röthler ve Wenzlaff, 2011: 11). Müzisyenleri ve diğer alanlardaki sanatçıları desteklemek amacıyla, 2003 yılında ABD'de kurulan "ArtistShare" isimli bir web sitesi, aralarında Grammy ödülü de alan birçok sanatçının projesini, destekçilerinden topladıkları paralarla gerçekleştirmelerine aracılık etmiştir. Bu nedenle, ArtistShare kitlesel fonlamayı kullanan ilk internet sitesi olarak kabul edilmektedir (Sakızl, 2018: 7). ArtistShare'in ilk kitlesel fonlama projesi, Maria Schneider'in caz albümü olmuştur. Maria Schneider, ArtistShare kampanyasıyla hayranlarından yaklaşık 130.000 \$ para toplamış ve çıkardığ albümle 2005 Grammy ödülü almıştır (Freedman ve Nutting, 2015:1). ArtistShare'in başarısı sonrasında, başta 2008 yılında Indiegogo ve 2009 yılında Kickstarter olmak üzere çok sayıda kitlesel fonlama platformu ortaya çıkmıştır. Sanat dallarına (güzel sanatlar, çizgi romanlar, dans, tasarım, moda, film ve video, müzik, fotoğrafçılık, yaratıcı yazarlık, tiyatro) ek olarak, sosyal konular (hayvanlar, topluluk, eğitim, çevre, sağlık, politika, din) ve girişimciler için de finansman kampanyaları yapılmaya başlanmıştır (Freedman ve Nutting, 2015:12).

Görüldüğü gibi, kitlesel fonlama, arkadaşlardan ve aileden fon toplama şeklindeki finansman yönteminin online uzantısı olarak başlamıştır. Girişimciler, interneti ve sosyal medyayı kullanarak, aile ve arkadaşlarının ötesinde, geniş bir kitleye ulaşmaya çalışarak, onlardan projeleri için fon talebinde bulunmaya başlamışlardır. Diğer bir deyişle, girişimciler, projelerini gerçekleştirmek için ihtiyaç duydukları parayı, çok küçük gruptan (aile, arkadaş vb.) veya geleneksel finansal kurumlardan almak yerine, her bireyin küçük tutarlarda katkıda bulunacağı çok sayıdaki kişiden toplamaya çalışmaktadırlar. Çok sayıdaki kişi, bir "kitleyi" (crowd) oluşturduğu için, bu yeni finansman yöntemini veya kaynağını tanımlamak için "kitlesel fonlama" (crowdfunding) terimi kullanılmıştır (Belleflamme, 2010: 1).

Kitlesel fonlamanın temel amacı belirli bir projeyi veya girişimi finanse etmektir. Yeni girişimlerin, ister banka kredileri ile olsun isterse özkaynak yoluyla olsun, ilk aşamalarında dış finansman bulmakta zorlandıkları bilinen bir gerçektir. Melek yatırımcılar ve girişim sermayesi ortaklıkları/fonları daha çok büyük yatırımları finanse ederken, nispeten daha küçük tutarlı girişimler, girişimcilerin kendileri ya da aile veya arkadaşları tarafından finanse

\footnotetext{
${ }^{1}$ Web 2.0 teknolojileri, 2003-2004 yıllarından sonraki dönemi, diğer bir ifadeyle, internet kullanıcılarının görüş ve düşüncelerini paylaşabilmelerine, çeşitli gruplar oluşturabilmelerine ve/veya gruplara katılabilmelerine, bilgiyi sadece alan değil üreten ve paylaşan konumuna geçmelerine imkân sağlayan web teknolojilerini ifade etmek için kullanılmaktadır. Web 2.0 teknolojilerine örnek olarak; Facebook, Twitter gibi sosyal ağ siteleri, bloglar, Youtube gibi video paylaşım siteleri, Wikipedia gibi içeriğin kullanıcılar tarafından oluşturulabildiği web siteleri ile Skype, Google Talk gibi anlık mesajlaşma/sohbet uygulamaları verilebilir (Işık, 2013).
} 
edilmektedirler. Bununla birlikte, kısmen yatırımcıları bulma ve ikna etmedeki başarısızlık, kısmen de girişimcilere yeterli değerin verilmeyişi nedeniyle birçok girişim finanse edilememektedir. Bu noktada kitlesel fonlama alternatif bir finansman kaynağı olarak devreye girmektedir (Belleflamme, 2010: 2).

Kitlesel fonlama, genel olarak müzik alanında ortaya çıkmış olsa da, kültür-sanat, film-fotoğraf, spor, moda-tasarım, teknoloji, turizm, eğitim, çevre gibi bir çok sektörde kullanılmaktadır. Dolayısıyla kitlesel fonlama projeleri, küçük sosyal veya sanatsal projelerden, on binlerce lira başlangıç sermayesi gerektiren kâr amaçlı projelere kadar, hem projenin amacı hem de projenin büyüklüğü açısından büyük bir yelpazeye sahiptir.

\section{KITTLESEL FONLAMA EKOSISTEMINDE TARAFLAR}

Kitlesel fonlama ekosisteminin nasıl çalıştığını anlamak açısından, paydaşları ve süreç üzerindeki etkilerini tanımlamak önemlidir. Genel olarak paydaş, "örgütün amaçlarına ulaşmasını etkileyebilecek veya bundan etkilenebilecek herhangi bir grup veya birey" anlamına gelmektedir Paydaşlar, izole gruplar olmayıp, birbirleriyle etkileşimde bulunan dinamik gruplardır (Beaulieu vd., 2015: 3). Kitlesel fonlama sistemindeki başlıca paydaşlar veya oyuncular üçe ayrılmaktadır. Bunlar; fon arayanlar, fon sağlayanlar ve kitlesel fonlama platformlarıdir.

\subsection{Fon Arayanlar}

Fon arayanlar, projelerini veya iş fikirlerini hayata geçirmek için ihtiyaç duydukları fonu toplamak amacıyla, kitlesel fonlama platformları aracılığıyla, geniş kitlelere açık çağrıda bulunan kişilerdir (Atsan ve Oruç Erdoğan, 2015: 305). Fon arayanlar, bireyler olabileceği gibi, vakıf, dernek gibi kâr amaçlı olmayan organizasyonlar veya ticari işletmeler de olabilir. Fon arayanlar kavramı yerine, "proje sahibi", "girişimci", "proje oluşturucusu", "kurucu" gibi kavramlar da kullanılmakla beraber, bu kavramların çoğu dar kapsamlı olup her zaman bütün katılımcıları ifade edememektedir. Örneğin, kitlesel fonlama yöntemiyle fon arayan bir kişi, bir iş kurma hedefine sahip olmayabilir veya farklı amaçlarla fon toplama girişiminde bulunabilir. Bu nedenle, "fon arayanlar" kavramı, ticari veya ticari olmayan farklı amaçlarla fon arayan kişileri, grupları, hayır kurumlarını, işletmeleri vb. kapsamaktadır (Beaulieu vd., 2015: 4).

Kitlesel fonlama, fon arayanların yerine getirilmemiş sermaye ihtiyacından kaynaklanmaktadır. Fon arayanların kitlesel fonlama ekosistemindeki rolü, bir iş fikri veya proje geliştirmek ve daha sonra bu projelerini kitlesel fonlama platformları aracilığıyla potansiyel fon sağlayanlara sunmaktır. Bunun için, fon arayan öncelikle projesine ilişkin ön hazırlık çalışması yapmalıdır. $\mathrm{Bu}$ kapsamda, projenin hayata geçirilmesinin toplam maliyetinin ne olacağı, bunun ne kadarının kitlesel fonlama aracılığıyla karşılanacağı, projenin ne kadar sürede hayata geçirileceği, projenin hayata geçirilmesi sürecinde yapılması gerekenler ve olası riskler, fon sağlayanlara verilecek ödüllerin yapısı ve sayısı gibi birçok açıdan projenin titizlikle hazırlanması gerekmektedir. Bu hazırlık çalışması yapıldıktan sonra, fon arayan, projesine uygun bir kitlesel fonlama platformu seçmelidir. Çünkü bazı platformlar belirli alanlardaki veya sektörlerdeki projelerde uzmanlaşmış ya da sadece belirli alan/sektörlerdeki projeleri kabul ediyor olabilir. Yine, bazı platformlar sadece belirli türdeki (bağış bazlı kitlesel fonlama projeleri, ödül bazlı kitlesel fonlama projeleri gibi) projeleri 
kabul ediyor olabilir. Bu nedenle, doğru hedef kitlesine ulaşmak için projenin türüne ve amacına uygun bir platform seçilmelidir.

Fon arayanlar, kitlesel fonlama platformuna karar verdikten sonra, platformun internet sayfasında, kendilerine ayrılmış sayfada projelerini sunarlar. Genellikle, projelerin sunulduğu bu sayfalar, platform tarafindan oluşturulmuş belirli şablonları içerir. Burada, fon arayanlar, zorunlu (fon arayanın ismi, hedeflenen fon tutarı, proje hakkında temel açıklayıcı bilgi gibi) ve isteğe bağlı (projeyle ilgili video, resim, proje hakkında daha detaylı bilgiler, proje ekibi hakkında bilgi, sosyal medya bağlantıları gibi) olarak projeleriyle ilgili bilgileri girerek projelerinin sayfasını oluştururlar. Fon sağlayanlardan toplanan fonların, fon arayanın hedeflediği fon tutarına ulaşması veya geçmesi durumunda proje "başarılı" olarak kabul edilmekte ve fon arayan, toplanan parayı platformdan alarak projesini hayata geçirmek için kullanabilmektedir. Ĕger, toplanan fon tutarı, fon arayanın hedeflediği fon tutarının altında kalmışsa, proje "başarısız" sayılmakta ve platform tarafindan fon arayana herhangi bir fon transferi yapılmamaktadır. Projelerin sadece kitlesel fonlama platformunda sunulması yeterli değildir. Projelerin başarılı olabilmesi, diğer bir deyişle hedeflenen fon tutarına ulaşılabilmesi için, fon arayanların kitlesel fonlama platformundaki proje sayfasını, özellikle sosyal medyayı ve diğer iletişim kanallarını kullanarak yayması, proje sayfasında güncellemeler yapması, gelen yorumlara cevap vermesi, potansiyel destekçilerle sürekli iletişim kurmaya çalışması gibi unsurlar büyük önem taşımaktadır (Röthler ve Wenzlaff, 2011: 5; Ania ve Charlesworth, 2015: 15; Daştan ve Gürler, 2018: 171; Vural ve Doğan, 2019: 91).

\subsection{Fon Sağlayanlar}

Kitlesel fonlama ekosistemi için diğer bir önemli paydaş fon sağlayanlardır. Fon arayanlar ve fon sağlayanlar iki temel taraf olup, bunlardan birinin olmaması durumunda bir piyasadan söz edilmesi mümkün değildir. Fon sağlayanlar; "destekçi”, "borç veren”, "yatırımcı", "müşteri", "katkıda bulunan" gibi kavramlarla da ifade edilmektedir (Beaulieu vd., 2015: 5). Fon sağlayanlar, birey olabileceği gibi finansal kurum ve işletmeler de olabilir. Dikkat edileceği üzere, fon arayanları ifade etmek için kullanılan kavramlardan biri de yatırımcıdır. Dolayısıyla, bazı bireyler ve özellikle kurumlar/işletmeler gelecek vaat eden projelere ortak olarak veya borç şeklinde finansman sağlayarak kâr payı ve faiz getirisi elde etmek amaciyla bu piyasaları kullanmaktadırlar.

Fon sağlayanlar, fon arayan girişimcilerin kitlesel fonlama platformlarında sundukları projeleri inceleyip, destek olmak istedikleri projelere para yatırarak projelerin hayata geçmesine katkıda bulunmaktadırlar. Yaptıkları katkı karşılığında, belirli bir maddi ödül/finansal getiri bekleyebilirler ya da herhangi bir maddi/finansal karşılık beklemeyebilirler. Fon arayanlar genellikle, bağış bazlı kitlesel fonlama projelerinde bir karşılık beklemez iken, ödül bazlı ve finansal bazlı (paya dayalı ve borca dayalı) kitlesel fonlama projelerinde bir karşıllk beklemekte veya talep etmektedirler (Pierrakis, 2019: 242). Fon sağlayanların katkıda bulundukları projenin başarısız olması, yani projenin hedeflenen fon tutarına ulaşamaması durumunda, fon sağlayanların hesaplarından para çekilmemekte veya çekilmiş ise iade edilmektedir (Kitlesel Fonlama Derneği, 2017: 10).

Fon sağlayanların, girişimcilerin projelerine para yatırarak katkı sağlamalarının ötesinde, başka fonksiyonları da bulunmaktadır. Fon sağlayanlar; projeyi veya proje kapsamındaki ürünü test etmede ve izlemeye değer olup olmadığ 1 konusunda karar vermede 
rol oynarlar. Aynı zamanda, sosyal medya ve kendi kişisel ağlarını kullanarak projenin tanıtımına katkıda bulunabilirler (Beaulieu vd., 2015: 5; Vural ve Doğan, 2019: 91).

\subsection{Kitlesel Fonlama Platformları}

Kitlesel fonlama platformları, bir web sitesi aracılığıyla, fon arayanlar ile fon sağlayanları bir araya getiren kuruluşlardır. Web sitesi şeklinde faaliyet gösterdikleri için bu platformlara "web sitesi sağlayıcıları" da denilmektedir. Dolayısıyla bu web sitesi sağlayıcıları, fon arayanların projelerini çok sayıda potansiyel destekçiye ulaştırmalarında teknolojik altyapıyı sağlamaktadır. Web sitesi sağlayıcıları kitlesel fonlama ekosisteminde önemli bir aktördür, çünkü bunların kitlesel fonlama sürecini oluşturmak, yönetmek, kontrol etmek ve sorunsuz şekilde çalışmasını sağlamak gibi rolleri bulunmaktadır. Ayrıca yasal gereklilikler ve denetimler de bunlar aracılığıyla uygulanmaktadır. Bu gibi nedenlerle, kitlesel fonlama platformları tüm paydaşlarla arayüz oluşturmakta ve ekosistemin merkezinde yer almaktadır (Beaulieu vd., 2015: 4).

Projeleri için fon arayan girişimciler, projelerinin türüne ve amacına uygun bir kitlesel fonlama platformunun web sitesine girmekte ve web sitesinde bulunan online başvuru formunu doldurarak proje başvurusunda bulunmaktadırlar. Platform, önerilen projeleri incelemekte ve uygun gördüklerinin platformda sunulmasına izin vermektedir. Platformlar; projelerin ön elemeden geçirilip uygun görülenlerin sunulmasına izin verilmesinin dışında, fon arayanların kendileri ve projeleri hakkında temel bilgilerin sunulmasını sağlama, proje güncellemeleri yapma, potansiyel veya mevcut destekçilerin proje hakkında yorum yapmasına imkân sağlama, proje sayfasından fon arayanın sosyal medya hesaplarına bağlanma imkanı sunma, fon sağlayanların güvenli bir şekilde ödeme yapmalarını sağlama, başarılı projeler için toplanan paraları fon arayanlara transfer etme gibi hizmetler de sunmaktadırlar. Bununla birlikte, başarılı projelerde, fon arayanların fon sağlayanlara vaat ettikleri ödülleri taahhüt ettikleri tarihte yerine getirmemeleri veya hiç yerine getirememeleri durumunda platformların herhangi bir sorumluluğu bulunmamaktadır (Kitlesel Fonlama Derneği, 2017: 11). Diğer bir ifadeyle, kitlesel fonlama platformlarının, fon arayanların sağladıkları fonu nasıl kullandıklarını denetlemek, fon sağlayanlara karşı sözlerini (vaatlerini) veya yükümlülüklerini (faiz ödemeleri gibi) yerine getirmelerini sağlamak gibi bir görev ve sorumlulukları yoktur.

Girişimciler ile potansiyel fon sağlayanları online bir pazar (web sitesi) aracılığıyla bir araya getiren ve sistemin işleyişinde önemli roller üstlenen kitlesel fonlama platformları kâr amacı güden kuruluşlardır. Platformlar, başarılı projelerde, toplanan tutarın belirli bir kısmını (\%5 ila \%10 arasında bir oran) komisyon olarak almaktadırlar (Atsan ve Oruç Erdoğan, 2015: 306; Çubukçu, 2017: 159). Bu komisyon platformların gelirini oluşturmaktadır. Başarılı projelerin sayısı arttıkça platformlar da daha fazla gelir edeceklerdir. Bu nedenle, platformlar başarılı olma olasılığı yüksek projeleri veya proje sahiplerini çekmek, başarılı olabilmelerini sağlamak için onları doğru yönlendirmek, sistemin iyi bir şekilde kurgulanıp güvenli bir şekilde işleyişini sağlamak, açık ve şeffaf olmak gibi konularda üzerlerine düşeni fazlasıyla yapmaya çalışacaklar, bu da bir bütün olarak piyasasının gelişmesine olumlu katkıda bulunacaktır. 


\section{KITTLESEL FONLAMA MODELLERİ}

Kitlesel fonlamada genel olarak iki fonlama modeli kullanılmaktadır. Bunlar; "ya hep ya hiç" (all-or-nothing) fonlama modeli ve "hepsi kalsın" (keep-it-all) fonlama modelidir (Freedman ve Nutting, 2015: 12). Ya hep ya hiç modelinde, belirlenen süre içerisinde fon sağlayanlardan toplanan tutar, proje sahibi tarafından belirlenen fon tutarının altında kalmış ise, proje başarısız olarak kabul edilmekte ve fon sağlayanların kredi kartlarından taahhüt etikleri paralar çekilmemektedir. Projenin başarısız olması durumunda, proje sahibi de herhangi bir fon alamamış olmaktadır. Örneğin, bir girişimci projesi için kampanya döneminin başında hedeflediği fon tutarını 10.000 TL olarak belirlemiş ve 60 günlük kampanya dönemi boyunca fon sağlayanlardan toplanan para 10.000 TL'nin altında kalmış ise, girişimci kitlesel fonlama aracılığıyla projesine fon sağlayamamış olmaktadır. Kampanya dönemi boyunca toplanan paranın 10.000 TL olması veya bu tutarı geçmesi durumunda, kitlesel fonlama platformu, toplanan paradan kendi komisyonunu keserek kalanı girişimcinin hesabına aktarmaktadır. Hepsi kalsın modelinde, kampanya döneminde toplanan tutar, girişimcinin hedeflediği fon tutarının altında kalmış olsa bile, girişimciye aktarılmaktadır. Hepsi kalsın modelinde, platformların aldığı komisyon oranları daha yüksek olabilmektedir. Ya hep ya hiç modelini kullanan projeler, hepsi kalsın modelini kullanan projelere göre, daha yüksek hedeflenen fon tutarına ve daha yüksek başarı olasılığına sahiptir (Cumming vd., 2020: 335).

\section{KİTLESEL FONLAMANIN TÜRLERİ}

Kitlesel fonlamanın dört temel türü bulunmaktadır. Bunlar; bağış bazlı kitlesel fonlama, ödül bazlı kitlesel fonlama, borç bazlı kitlesel fonlama ve pay (özsermaye) bazlı kitlesel fonlamadir (Nesta, 2012: 2; Chervyakov ve Rocholl, 2019: 5). Kitlesel fonlama türleri, finansal olmayan kitlesel fonlama ve finansal kitlesel fonlama olarak da iki gruba ayrılabilmektedir (Bijkerk, 2014; Onur ve Değirmenci, 2015: 2). Bağış bazlı ve ödül bazlı kitlesel fonlama finansal olmayan, borç bazlı ve pay bazlı kitlesel fonlama ise finansal fonlama grubunda yer almaktadır. Çünkü bağış ve ödül bazlı kitlesel fonlamalarda, fon sağlayanların amacı finansal getiri elde etmek değildir. Buna karşın, fon sağlayanların amacı, borç bazlı kitlesel fonlamada faiz getirisi, pay bazlı kitlesel fonlamada ise kâr payı ve/veya değer artış kazancı elde etmektir. Bu nedenle, borç bazlı ve pay bazlı kitlesel fonlama projelerine para (borç şeklinde veya öz sermaye şeklinde) yatıranlara "yatırımcı", kitlesel fonlamanın bu türüne "kitlesel yatırım" (crowdinvesting) da denilmektedir. Kitlesel yatırımla, melek yatırımcılar ve girişim sermayesi fonları/ortaklıklarından farklı olarak, bireyler de gelecek vaat eden projelere küçük tutarlar halinde yatırım yapma imkânı elde etmiş olmaktadırlar (Fettahoğlu ve Khusayan, 2017: 507).

\subsection{Bağış Bazlı Kitlesel Fonlama}

Bağış bazlı kitlesel fonlama, sosyal veya hayır amaçlı projeler için kitlelerden (halktan) para toplanması ve söz konusu projelerin finanse edilmesidir (Röthler ve Wenzlaff, 2011: 12; Nesta, 2012: 2). Bağış bazlı kitlesel fonlama projeleri kâr amacı gütmeyen hayır amaçlı projelerdir. "Bağış bazlı" denilmesinin nedeni, kampanyayı yürüten hayır kurumunun veya proje sahibinin, destekçilere sağladıkları fon karşılığında maddi veya maddi olmayan herhangi bir ödül/getiri sunulmamasıdır. Diğer bir ifadeyle, destekçiler, bu tür projeleri herhangi bir karşılık/getiri beklentisi olmadan başkalarına yardımcı olmak veya projeye 
katkıda bulunmak amacıyla finanse etmektedirler (Atsan ve Oruç Erdoğan, 2015: 302; Sakızlı, 2018: 11). Bir karşılık olmasa da projeye katkıda bulunan destekçilere; teşekkür epostası gönderme, bir web sitesinde bağış̧̧̧ların adlarının yer alması, çiçek gönderilmesi, belirli bir etkinliğe davet etme, hayır kurumunun logosunu taşıyan küçük ürünler hediye etme gibi sembolik ödüller sunulabilmektedir.

Büyük hayır kurumları kendi web siteleri üzerinden bă̆ış toplayabilmekte veya çeşitli bağış kampanyaları düzenleyebilmektedir. Fakat bağış bazlı kitlesel fonlama platformlarının ortaya çıkmasıyla, küçük hayır kurumları ve bireyler de hayır amacıyla geniş kitlelerden fon toplama imkânı elde etmişlerdir. Örneğin, bağış bazlı kitlesel fonlama platformu olarak 2010 yılında kurulan GoFundMe, kurulduğu yıldan 2020 yılına kadar, 120 milyondan fazla katılımcıdan 9 milyar \$'ın üzerinde bağışın toplanmasına aracılık etmiştir (www.gofundme.com/c/about-us).

\section{2. Ödül Bazlı Kitlesel Fonlama}

Ödül bazlı kitlesel fonlama türünde, fon arayanlar, projelerine fon sağlayarak katkıda bulunanlara (fon sağlayanlara), yaptıkları katkı tutarına göre çeşitli maddi/maddi olmayan ödüller vermektedirler (Nesta, 2012: 3). Bu ödüller ya hep ya hiç modelinde, proje başarılı olduğunda, yani toplanan fon tutarı hedeflenen fon tutarına ulaştı̆̆ında geçerli olacak ve girişimcinin önceden taahhüt ettiği tarihlerde fon sağlayanlara verilecek ödüllerdir. Başarılı olmayan projelerde, girişimci fon alarak projesini hayata geçiremediği için, fon sağlayanlar da vaat edilen ödülleri alamayacaklardır. Teşekkür epostası/kartı gönderme, proje kapsamındaki ürünü öncelikli veya indirimli satın alma hakkı verme, projede adının geçmesini sağlama, ürün/proje logolu çeşitli ürünler gönderme, proje ekibiyle buluşma ve yemek yeme, projeye katılma, çeşitli etkinlikler için davetiye gönderme gibi çok çeşitli ödüller olabilmektedir (Çubukçu, 2017: 159; Açıkgöz vd., 2020: 60). Bu ödüller, yapılan katkı tutarına göre küçükten büyüğe doğru sıralanmaktadır. Örneğin, bir kısa film projesinde, projeye $50 \mathrm{TL}$ katkıda bulunanlara bir teşekkür e-postası gönderilebilirken, 500 TL katkıda bulunanlara bir link üzerinden filmi izleme imkânı sunulabilir. Ödül bazlı kitlesel fonlamada, bazı veya çoğu ödüllerin maddi değeri, yapılan katkının altında olabilir. Bu açıdan, ödül bazlı kitlesel fonlama bağış bazlı kitlesel fonlamaya benzemekle birlikte, genellikle projelerin kâr amaçlı ve yaratıc1/yenilikçi olmaları ve fon sağlayanların bu tür projeleri hem içsel/sosyal motivasyon (yardım etme, başkasını düşünme, faydalı olma hissi vb.) hem de dışsal motivasyonla (bir ödül/karşılık beklentisi) desteklemeleri gibi açılardan farkl1lıklar içermektedir. Bu nedenle, ödül bazlı kitlesel fonlama projelerinde sunulan ödüllerin sayısı ve neler olduğu projelerin başarışını etkileyen önemli faktörlerden birini oluşturmaktadır (Kunz vd., 2016: 472; Paakkarinen, 2016: 27; Dikaputra vd., 2019: 9).

Ödül bazlı kitlesel fonlama; sosyal, kültürel ve yaratıcı projelerin ve iş fikirlerinin finansmanında yaygın olarak kullanılan bir kitlesel fonlama türüdür. $\mathrm{Bu}$ fonlama türü kullanılarak; güzel sanatlar, dans, tasarım, moda, film ve video, müzik, fotoğrafçılık, yaratıcı yazarlık, tiyatro, eğitim, çevre, sağlık, gıda, spor, oyun, yayıncılık, teknoloji gibi birçok kategorideki projenin finansmanını sağlayabilmek mümkündür (Freedman ve Nutting, 2015: 12; Sakızlı, 2018: 12). 


\subsection{Borç Bazlı Kitlesel Fonlama}

İşlem hacmi bakımından kitlesel fonlama pazarından en büyük payı alan borç bazlı kitlesel fonlama, kredi (borç) almak isteyen taraflar ile borç vermek isteyen tarafların, bir kitlesel fonlama platformu aracılığıyla eşleştirilmesidir (Kirby ve Worner, 2014: 9). Borç almak için platforma başvuran taraflar; bireyler, girişimciler veya küçük işletmeler olabilir. Benzer şekilde, borç vermek isteyen taraflar da bireyler, işletmeler veya finansal kurumlar olabilir. Borç bazlı kitlesel fonlama, yatırım veya finansal bazlı bir kitlesel fonlama türüdür, çünkü kredi verenler faiz getirisi almak için bu piyasaya girmektedirler. "Taraflararası borç verme" (peer-to-peer lending) olarak da ifade edilen bu fonlama türünde, iş fikrini hayata geçirmek isteyen girişimciler, fona ihtiyacı olan küçük işletmeler veya eğitim masraflarını karşılamak, evini yenilemek, araba almak/arabasını değiştirmek isteyen bireyler kredi almak için platforma başvurmakta, bu başvurular gerekli incelemelerin ardından platform tarafından onaylanmakta veya ret edilmekte, onaylanan kredi başvuruları platformun web sitesinde yayınlanmakta ve yatırımcılar da kendi risk-getiri profillerine göre istedikleri kredileri finanse etmektedirler (Freedman ve Nutting, 2015:13; Möllenkamp, 2017: 2). Burada, kitlesel fonlamanın mantığına uygun şekilde, bir kredi, küçük tutarlar şeklinde borç veren çok sayıdaki yatırımcı tarafından finanse edilmiş olmaktadır. Dolayısıyla bir birey, girişimci veya işletme, çok sayıdaki kişiden (kitlelerden) borç almakta ve daha sonra faiziyle geri ödemektedir. Bu kitlesel fonlama türünde de, platform aracılığıyla borç almak isteyen taraf (borçlu), almak istediği borç tutarını belirlemekte ve eğer borç verenler tarafından taahhüt edilen kredi miktarı hedeflenen borç tutarına ulaşır veya geçerse proje "başarılı" sayılmakta ve bu durumda, platform toplanan krediyi borçluya vermektedir. Borç verenler tarafindan taahhüt edilen kredi miktarı borçlunun talep ettiği kredi tutarının altında ise, proje "başarısız" sayılmakta ve borçlu istediği/talep ettiği krediyi alamamış olmaktadır.

Borçluların geleneksel kredi kurumlarımdan borç almak yerine, bu geleneksel kurumları aradan çıkarıp, borç bazlı kitlesel fonlama yöntemiyle doğrudan kitlelerden borç almalarının temel nedeni, borçlanma maliyetlerinin (faiz oranlarının) daha düşük olması, internet üzerinden kolayca erişilebilir olması ve/veya geleneksel kredi kurumlarından kefilsiz/teminatsız borç alma imkânlarının düşük olmasıdır (Möllenkamp, 2017: 2). Borçlunun kişisel bilgi ve ödeme geçmişine bağlı olarak hesaplanan bir kredi risk puanına göre genellikle platform tarafından belirlenen kredi faiz oranları, borç verenler açısından getiriyi oluşturmaktadır. Borç verenlerin bu piyasayı tercih etmelerinin nedeni, bu faiz oranlarının genellikle mevduat faizi, repo gibi geleneksel para piyasası araçlarının getirisinden daha yüksek olmasıdır (Röthler ve Wenzlaff, 2011: 12; Polena ve Regner, 2016: 2; Xiao vd., 2018: 825). Borç bazlı kitlesel fonlamada platformların geliri, talep edilen kredi tutarının belirli bir yüzdesi olarak borçludan alınan komisyon ile yatırımcılardan alınan kredi hizmet ücretinden (yıllık sabit bir ücret veya verilen kredi tutarının belirli bir yüzdesi) oluşmaktadır (Freedman ve Nutting, 2015:13).

\subsection{Pay Bazlı Kitlesel Fonlama}

Kitlesel fonlama uygulamasının diğer bir türü, işletmelere veya projelere özsermaye yatırımına ve kâr paylaşımına imkân veren, pay (özsermaye) bazlı kitlesel fonlamadır. Kitlesel fonlamanın bu türü, düzenleyici kısıtlamalar nedeniyle diğer türlere göre daha az gelişmiştir, dolayısıyla kitlesel fonlama piyasası içinde en düşük işlem hacmine sahiptir (Nesta, 2012: 3; Kirby ve Worner, 2014: 10). Yeni bir işletme kurarak iş fikirlerini hayata 
geçirmek isteyen girişimciler veya yaratıcı iş fikirlerine sahip küçük ölçekli işletmeler ya da büyüme-gelişme potansiyeli olan yeni kurulmuş işletmeler bu finansman yöntemini kullanarak finansman ihtiyaçlarını giderebilirler. Bir girişimcinin projesiyle ilgilenen melek yatırımcıları veya girişim sermayesi ortaklıkların//fonlarını bulması ve bir anlaşmayı müzakere etmesi genellikle sekiz ila on iki ay sürmesine karşın, pay bazlı kitlesel fonlama platformlarında bu süre günler veya haftalarla ifade edilebilmektedir (Freedman ve Nutting, 2015: 15). Pay bazlı kitlesel fonlamada, girişimciler iş fikirlerini yatırımcılara platform aracılı̆ğyla sunmakta ve projenin (mevcut veya kurulacak yeni işletmenin) gelecek vaat ettiğini düşünen yatırımcılar işletmenin paylarını satın alarak işletmeye ortak olmaktadırlar. Girişimciler, sadece bir yatırımcıya veya sınırlı sayıdaki yatırımcıya ulaşmak yerine, çok sayıdaki yatırımcıdan küçük tutarlar şeklinde topladığı fonla, hem daha hızlı bir şekilde hem de işletmesinin yönetimini elinde tutarak finansman ihtiyacını gidermiş olmaktadırlar. Pay satın olarak projeye/işletmeye ortak olan yatırımcıların amacı ise, kârdan pay almak, oy hakkı elde etmek ve/veya değer artış kazancı sağlamak olabilir (Röthler ve Wenzlaff, 2011: 13). Yatırımcılar, diğer pay yatırımlarında olduğu gibi, işletmenin başarısız olma veya zarar etme riskini almış olmalarının dışında, ikincil piyasanın olmayışı veya gelişmemiş olmasıı nedeniyle likidite riskini de almaktadırlar (Kirby ve Worner, 2014: 20).

Pay bazlı kitlesel fonlamada, girişimci ihtiyaç duyduğu fonu sağlamak amaciyla kitlesel fonlama platformu üzerinden bir kampanya (satış süreci) başlatmaktadır. Birim pay fiyatı, satışa konu pay sayısı, hedeflenen fon tutarı (birim pay fiyatı x satışa konu pay sayısı), kampanya süresi, satı̧̧a konu payların sermaye içindeki payı, satıştan gelecek paranın hangi amaçla kullanılacağı, işletmeyle ilgili çeşitli mali veriler gibi bilgiler yatırımcılarla paylaşılmaktadır (Onur ve Değirmenci, 2015: 3). Kampanya süresi içinde yatırımcılardan toplanan fon tutarının hedeflenen fon tutarına ulaşması veya bu tutarı geçmesi durumunda kampanya "başarılı" sayılmaktadır. Örneğin, bir girişimci işletmesine ait 50.000 adet payı, birim satış fiyatı 10 TL'den iki aylık bir süre içerisinde satmak amacıyla kitlesel fonlama platformunda bir kampanya oluşturmuşsa, kampanyanın başarılı sayılması ya da fonlamanın gerçekleşmiş olması için, yatırımcılardan toplanan toplam fon tutarının en az 500.000 TL (10 TL x 50.000 adet) veya üzerinde olması gerekmektedir. Kampanyanın başarılı olması durumunda, yatırımcilardan toplanan ve bir emanet hesapta tutulan fonlar işletmenin hesabına transfer edilirken, paylar da yatırımcıların hesaplarına dağıtılmaktadır. Girişimcinin hedeflenen fon tutarına ulaşamaması, diğer bir deyişle, kampanyanın başarısız olması durumunda, emanet hesapta toplanan fonlar yatırımcılara iade edilmektedir. Pay satışında girişimci ile yatırımcılar arasında aracı rolünü üstlenen kitlesel fonlama platformu, pay satışından sağlanan toplam fon tutarının belirli bir yüzdesini komisyon olarak almaktadır (Kirby ve Worner, 2014: 20).

\section{KITTLESEL FONLAMANIN GELENEKSEL FONLAMADAN ÜSTÜNLÜKLERİ VE OLASI RİSKLER}

Geleneksel finansal kurumların fon arayanlar ile fon sağlayanlar arasındaki aracıllk rolü, genel olarak, kitlesel fonlamada sisteminde de mevcuttur. Fakat kitlesel fonlamanın geleneksel fonlamadan bazı önemli farklılıkları ve üstünlükleri vardır. Kitlesel fonlamanın farklılıkları ve üstünlükleri şu şekilde ifade edilebilir:

- Daha Fazla Kişiye Ulaşma İmkânı: Kitlesel fonlama, fon ihtiyacı olan özellikle genç ve yeni girişimcilerin aile, arkadaş ve yakın çevresine olan bağımlılığını 
azaltarak geniş kitlelerden fon talep etmesine imkân vermektedir (Atsan ve Oruç Erdoğan, 2015: 309). Böylelikle kitlesel fonlama yenilikçi fikirleri olan ama projelerini finanse etmek için gerekli başlangıç sermayesine erişimi olmayanların projelerini hayata geçirebilmelerinin önünü açmaktadır (Bannerman, 2012: 4).

- Zaman ve Coğrafi Sınır Engellerini Ortadan Kaldırması: Girişimciler, projelerini kitlesel fonlama platformları aracılı̆̆ıyla, belirli bir süre için, potansiyel fon sağlayanların sürekli incelemesine sunmaktadırlar. Ayrıca burada coğrafi engeller veya sınırlar da söz konusu değildir. Diğer bir ifadeyle, dünyanın her tarafındaki potansiyel fon sağlayanlar kitlesel fonlama platformları aracılığıly girişimcilerin projelerine günün her saati ulaşabilir, inceleyebilir, kendi sosyal ağlarında projeyi paylaşabilir ve isterlerse fon sağlayarak destek olabilirler (Paakkarinen, 2016: 33).

- $\quad$ Sermayenin Demokratikleşmesi ve Şeffaflık: Bankalar veya diğer geleneksel yatırımcılar, iş stratejilerine uymayan veya risk-getiri açısından beklentilerini karşılamayan projeleri ya da iyi bir geçmişe (sicile) sahip olmayan girişimcilerin projelerini finanse etme eğiliminde değillerdir (Holtland ve van Heck, 2019: 8). Girişimciler; bankaları, risk sermayedarlarını, melek yatıımcıları ya da diğer geleneksel aracıları atlayabilmekte ve böylece fonlama süreçlerini daha şeffaf ve demokratik hale getirebilmektedirler. Kitlesel fonlamanın temelini internet ve sosyal ağ oluşturmaktadır. Dolayısıyla, kitlesel fonlama sosyal ağ ve internetin gayri resmi işbirliği modellerini finansman dünyasına aktarmakta ve finansmanda demokratikleşme ve şeffaflığa yol açmaktadır. İş fikri olan ve projesine güvenen herkes kitlesel fonlama aracıllğıyla projesini sunabilir ve fon talebinde bulunabilir. Fon sağlayanlar ise istedikleri projelere küçük tutarlarla ve fazla bir riske girmeden destek olabilirler (Röthler ve Wenzlaff, 2011: 5).

- $\quad$ Spesifik Olması ve Değer Değişimi: Genel bir amaç veya misyon için destek istemenin aksine, kitlesel fonlama projeleri daha spesifiktir ve içinde belirli "temas noktaları" barındırmaktadır. $\mathrm{Bu}$ temas noktaları, fon sağlayanlarda farklı duygular ve tepkiler oluşturarak projeye destek olma kararında etkili olabilmektedir. Kitlesel fonlamanın diğer bir özelliği, fon arayanları, destekçileri için oluşturdukları değeri artırmaya teşvik etmesidir. Yaratılan değer (duygusal bağ kurarak, şaşırtarak, eğlendirerek, mal ve hizmetler sunarak vb.) arttıkça, fon sağlayanların projeye katkıda bulunma olasılığı da artmaktadır. Bu nedenle, fon arayanlar, "benim için ne var" sorusuyla projeleri inceleyen potansiyel fon sağlayıcılarını ikna etme etmek için projelerinin çıktıları ve yarattı̆̆ değer konusunda daha fazla çaba göstereceklerdir (Ania ve Charlesworth, 2015: 13).

- Basitlik ve Kolaylık: Fon arayanlar, kitlesel fonlama platformları aracıllğıyla projelerini hedefledikleri destekçilere daha kolay bir şekilde sunabilirler. Kitlesel fonlama, fon arayanlara; fon toplama çabalarını merkezileştirme, düzene sokma ve kolay yönetebilme imkânı sunmaktadır. Diğer bir ifadeyle, fon arayanlar, tek bir profil (proje) sayfası oluşturarak, projelerini tanıtabilmekte, tüm potansiyel müşterileri veya fon sağlayanları bu sayfaya yönlendirebilmekte, onlarla bu profil sayfası üzerinden iletişim kurabilmekte ve fon toplayabilmektedir (Holtland ve van Heck, 2019: 7).

- Piyasa Araştırması ve Pazarlama Aracı Olarak Kullanılması: Kitlesel fonlama, girişimcilerin ürünlerini test etmelerine, tanıtmalarına ve pazarlamalarına, tüketicilerinin zevkleri hakkında daha iyi bilgi edinmelerine veya yeni ürünler oluşturmalarına yardımcı olmaktadır (Belleflamme, 2010: 2; Sakızlı, 2018: 13). Girişimciler, potansiyel müşterilerin veya fon sağlayıcıların projelere ya da proje kapsamındaki ürünlere verdikleri tepkilere ve yaptıkları geri dönüşlere göre, müşterilerin beklenti ve tercihleri hakkında bilgi sahibi olabilmekte ve buna göre ürünlerini piyasaya çıkarmadan önce gerekli değişiklikleri 
yapma imkânı elde etmektedirler (Holtland ve van Heck, 2019: 7). Kitlesel fonlama aracılı̆ğyla bir ürünün ön-satışa sunulması, ürünün piyasaya sürülmesi durumunda oluşacak talebe ilişkin bir bilgi vermektedir (Agrawal vd., 2014: 72). Girişimciler, bu değerli bilgiyi kullanarak yüksek maliyetlere katlanmadan projeden vazgeçilir veya projelerinde değişiklik yapabilirler.

- Daha Düşük Sermaye Maliyeti ve Daha Yüksek Getiri İmkânı Sunması: Kitlesel fonlamanın önemli üstünlüklerinden biri de fon arayanlara daha düşük maliyetle fon bulma imkânı, fon sağlayanlara da daha yüksek getiri elde etme imkânı sunmasıdır. Kitlesel fonlama, tasarrufları reel ekonomiye, genellikle geleneksel fonlama yollarıyla elde edilenden daha düşük bir maliyetle kanalize etmektedir (Kirby ve Worner, 2014: 4). Başvuruların incelenmesi, kredi analizi, fonların toplanması, proje sahiplerine transfer edilmesi gibi işlemler otomatik olarak gerçekleştirildiğinden kitlesel fonlama platformlarının maliyetleri daha düşük olmakta ve bunu müssterilerine (fon arayanlara) yansıtmaktadırlar (Freedman ve Nutting, 2015: 14). Bunun dişında, kitlesel fonlama projelerini farklı beklenti ve motivasyonlara sahip çok sayıdaki kişinin finanse etmesi de toplanan fonların maliyetini düşüren bir unsurdur (Agrawal vd., 2014: 71). Finansal (borç bazlı ve pay bazlı) kitlesel fonlamada, finansal getiri (kâr payı, faiz, değer artış kazancı) elde etmek amacıyla kitlesel fonlama projelerine yatırım yapanlar, mevduat faizi gibi geleneksel para piyasa araçlarının getirisine göre daha yüksek getiri elde edebilmektedirler (Röthler ve Wenzlaff, 2011: 12; Xiao vd., 2018: 825).

- $\quad$ Riski Yaymasi: Kitlesel fonlamada çok sayıda kişiden küçük tutarlar şeklinde fon toplandığı için, projenin başarısız olması, işletmenin iflas etmesi, destek karşıllı̆ında taahhüt edilen ödüllerin teslim edilmemesi, kitlesel fonlama aracilığıyla borç alan işletmenin yükümlülüklerini yerine getirmemesi/getirememesi gibi durumlarda, fon sağlayanların kaybı daha sinırlı olmaktadır (Kirby ve Worner, 2014: 4).

Her finansman yönteminin üstünlük ve sakıncaları olduğu gibi, kitlesel fonlamanın da bazı sakıncaları ve riskleri vardır. Fon arayanlar açısından bu risklerden biri, projenin kitlesel fonlama platformu tarafindan kabul edilmemesi veya kabul edilse de belirlenen süre içerisinde hedeflenen fon tutarına ulaşılamamasıdır (Holtland ve van Heck, 2019: 8). Bazı genç ve tecrübesiz girişimciler, projenin hazırlanması, sunulması, potansiyel fon sağlayanlarla iletişimin kurulması gibi açılardan fon bulma sürecini iyi yönetemeyebilir ve başarısız olabilirler (Fettahoğlu ve Khusayan, 2017: 506). Başarısız olan projeler, kitlesel fonlama platformunun web sitesinde kalmaya devam etmektedir. Bu durum bazı girişimcilerin şevkini kırabilir. Fon sağlayanlar açısından da bazı riskler söz konusudur. Örneğin, ödül bazlı kitlesel fonlamada, fon arayanlar toplanan fonlar karşıllı̆ında vaat ettikleri ödülleri zamanında teslim etmeyebilirler veya hiç teslim edemeyebilirler. Finansal bazlı kitlesel fonlamada ise, fon arayanlar, faiz ve anapara geri ödemeleri gibi yükümlülüklerini yerine getiremeyebilirler. Pay bazlı kitlesel fonlamada, ikincil piyasaların gelişmemiş olması nedeniyle, yatırımcılar ellerindeki payları satarak likide dönme konusunda sıkıntı yaşayabilirler. Fon arayanlar, projeleriyle ilgili tüm bilgileri açıklamayabilir veya olası riskler hakkında bilgi vermeyebilirler. Bu durum, fon sağlayanlar açısından asimetrik bilgi ve şeffaflık sorununa yol açabilmektedir (Kirby ve Worner, 2014: 5; Polena ve Regner, 2016: 2. Kitlesel fonlamay1 kullanarak fon arayacak ve fon sağlayacak olanların bu riskleri göz önünde bulundurmaları önemlidir. 


\section{DÜNYADA VE TÜRKIYYE'DE KITTLESEL FONLAMA}

Tarihte kitlesel fonlama mantığı kullanılarak, geniş kitlelerden yardım, bağış adı altında toplanan küçük tutarlarla belirli projelerin hayata geçirildiği birçok örnek olmasına karşın, günümüzdeki anlamıyla, 2003 yılında ABD'de kurulan ArtistShare isimli bir web sitesi dünyada ilk kitlesel fonlama platformu olarak kabul edilmektedir (Freedman ve Nutting, 2015:12; Vural ve Doğan, 2019:90). ArtistShare, başta müzisyenler olmak üzere sanatç1ların hayranlarından toplayacakları katkılarla projelerini gerçekleştirmelerini sağlamak amacıyla kurulmuş ve kısa zamanda önemli başarılar elde etmiştir. ArtistShare'in başarısının ardından, yine ABD'de, bugün de faaliyetlerini sürdürmekte olan ve kendi alanlarında önemli bir işlem hacmine sahip olan Indiegogo isimli ödül bazlı kitlesel fonlama platformu 2008 yılında, Kickstarter isimli ödül bazlı kitlesel fonlama platformu 2009 yılında kurulmuştur. Bunları çok sayıda platformun kuruluşu izlemiş ve 2018 yılı itibariyle ABD'de kurulan kitlesel fonlama platformlarının sayısı 900'e ulaşmıştır (Chervyakov ve Rocholl, 2019: 2). Kitlesel fonlama platformları, öncelikle İngiltere ve Avrupa Birliği (AB) ülkelerinde olmak üzere tüm dünyaya hızla yayılmaya başlamıştır. Ocak 2018 itibariyle, dünyadaki toplam kitlesel fonlama platformlarının sayısı 2.948'e ulaşmıştır. $\mathrm{Bu}$ platformların çoğu AB ülkelerinde (1.231 platform) yer almaktadır. Avrupa'da, kitlesel fonlama platformlarının sayısı ve işlem hacmi bakımından İngiltere, Fransa, Hollanda ve Almanya ilk sıralarda yer almaktadır (Chervyakov ve Rocholl, 2019: 2). ABD ve Avrupa'nın dışında, Asya'da kitlesel fonlamanın en gelişmiş olduğu ülke Çin'dir. İlk kitlesel fonlama platformunun 2011 yılında kurulduğu Çin'de, 2016 y1lı itibariyle toplam platform sayısı 332'ye ulaşmıştır (Huang vd., 2018: 304). İşlem hacmi bakımından kitlesel fonlamanın en önemli türü olan borç bazlı kitlesel fonlama türünde, ilk platform 2005 yılında İngiltere'de (Zopa) ve ardından 2006 yılında ABD'de (Prosper) kurulmuştur (Xiao vd., 2018: 825). 2007 yılında Avustralya'da ASSOB (Australian Small Scale Offerings Board) adıyla kurulan ve bugün faaliyetini "Enable Funding” olarak sürdüren platform, dünyanın ilk pay bazlı kitlesel fonlama platformudur (infoDev, 2013: 46; CFIA, 2020). Farklı veri bankalarına ve araştırma kuruluşlarının raporlarına göre değişmekle birlikte, CCAF (Cambridge Centre for Alternative Finance)'e göre, küresel bazda kitlesel fonlama piyasasının işlem hacmi 2015 yılında 139 milyar \$ iken, 2018 yılında 305 milyar \$'a ulaşmıştır. 2018 yılı itibariyle, 215,4 milyar \$'lık işlem hacmi $(\% 70,73)$ ile Çin ilk sırada, 61,1 milyar \$'lık işlem hacmi (\%20) ile ABD ikinci sırada ve 10,4 milyar \$'lık işlem hacmi $(\% 3,40)$ ile İngiltere üçüncü sırada yer almaktadır (P2PMarketData, 2020). Görüldüğü üzere, Çin toplam işlem hacminin yaklaşık \%71'ini tek başına gerçekleștirmiştir. Verilerin toplandığ 171 ülke içinde, ilk üç sıradaki ülkelerin toplam işlem hacmi içindeki paylarının toplamı \%94,2 olup, geriye kalan 168 ülkenin kitlesel fonlama işlem hacmi içindeki paylarının toplamı sadece $\% 5,8^{\prime}$ 'tir.

Kitlesel fonlamanın ABD'den İngiltere'ye ve oradan diğer ülkelere yayılmaya başlamasıyla beraber, Türkiye'de de ilk kitlesel fonlama platformu "Projemefon" adıyla 2010 yılında kurulmuştur. Bu platform, 2013 yılında el değiştirmiştir ve "crowdFON" adıyla faaliyetine devam etmektedir (StartUp, 14.02.2015; www.crowdfon.com). Projemefon'un ardından 2012 yılında FonlaBeni ve BiAyda, 2013 yılında FonGoGo, 2016 yılında ArıKovanı ve Buluşum, 2017 yılında İdeanest gibi kitlesel fonlama platformları kurulmuştur.

Türkiye'de 2017 y1lına kadar kitlesel fonlamayla ilgili bir yasal düzenleme yapılmamıştır. Faaliyet gösteren kitlesel fonlama platformları, bağış ve/veya ödül bazlı olup, mevcut yasalar çerçevesinde kurulmakta ve faaliyetlerini sürdürmektedirler. Borç bazlı ve pay 
bazlı kitlesel fonlama platformlarının kurulamamasının nedeni, yasal engeller olmuştur. 5 Aralık 2017 tarihinde Resmi Gazete'de yayımlanarak yürürlüğe giren 7061 sayılı "Bazı Vergi Kanunları ile Diğer Bazı Kanunlarda Değiş̧iklik Yapılmasına Dair Kanun” ile 6362 sayılı Sermaye Piyasası Kanunu'nda yapılan düzenlemeler çerçevesinde, kitlesel fonlama sermaye piyasası mevzuatına girmiştir. İkincil düzenleme kapsamında ise, Sermaye Piyasası Kurulu'nun (SPK) hazırladığı "Paya Dayalı Kitle Fonlaması Tebliği” 3 Ekim 2019 tarihinde Resmi Gazete'de yayımlanarak yürürlüğe girmiştir. Böylece Türkiye'de pay bazlı kitlesel fonlamanın yasal altyapısı oluşturulmuş, projelerine kaynak arayan girişimcilerin ve gelişme potansiyeli olan işletmelerin kitlesel fonlama platformları aracılı̆̆ıyla pay satarak finansman ihtiyaçlarını giderebilmelerinin önü açılmıştır. Bu Tebliğe göre, girişimciler ve işletmeler, herhangi bir 12 aylık dönemde kitle fonlama platformları aracılığıyla en fazla iki kampanya düzenleyerek fon toplayabileceklerdir. En fazla 60 gün olabilecek kampanya süresinin sonunda, yatıımcilardan toplanan fon tutarının hedeflenen fon tutarını geçmesi durumunda, kampanya başarılı sayılacak ve girişimci tarafindan kurulacak yeni işletme veya mevcut kurulu işletme tarafindan toplanan fon tutarı kadar yapılacak sermaye artırımı karşıllığında çıkarılacak paylar yatırımcıların hesaplarına, bloke hesapta tutulan fonlar ise işletmeye aktarılacaktır (SPK, Paya Dayalı Kitle Fonlaması Tebliği, md.16-17). Bu tür yatırımların riskli olması nedeniyle ve yatırımcıları korumak amacıyla, Tebliğde, nitelikli yatırımc1 ${ }^{2}$ vasfını taşımayan bireysel yatırımcılar için yatırım sınırlaması getirilmiştir. Buna göre, bireysel yatırımcılar bir yıl içerisinde pay bazlı kitlesel fonlama yoluyla en fazla 20.000 TL yatırım yapabileceklerdir. Ancak bu sınır 100.000 TL'yi aşmamak kaydıyla yatırımcının yıllık net gelirinin \%10'u olarak da uygulanabilecektir (SPK, Paya Dayalı Kitle Fonlaması Tebliği, md.15).

SPK, sadece pay bazlı kitlesel fonlamaya ilişkin yasal düzenleme yapmıştır. Diğer bir ifadeyle, bağış bazlı, ödül bazlı ve borç bazlı kitlesel fonlamaya ilişkin bir düzenleme söz konusu değildir. Zaten Paya Dayalı Kitle Fonlaması Tebliği'nde de, platformlar aracilığıyla ödül veya bağış karşıllı̆ıında fon toplanması faaliyetlerinin söz konusu Tebliğin kapsamına girmediği ifade edilmiştir. $\mathrm{Bu}$ nedenle, daha önce olduğu gibi, bağış veya ödül bazlı platformlar mevcut yasalara göre faaliyetlerini sürdürmeye devam edeceklerdir. Mevcut durumda borç bazlı kitlesel fonlamanın önünde yasal engeller olduğu için ve buna yönelik bir düzenleme yapılmadığı için, Türkiye'de borç bazlı kitlesel fonlama platformlarının kurulması veya borç bazlı kitlesel fonlama faaliyetlerinin yapılması yasal olarak mümkün değildir. Pay bazlı kitlesel fonlamanın mümkün hale gelmesiyle birlikte, FonGoGo.Pro ve StartUp gibi platformlar girişimcilerin pay karşılığında fon toplamalarına aracılık yapmak amacıyla gerekli altyapı çalı̧̧malarına başlamışlardır. Pay bazlı kitlesel fonlamaya ilişkin uygulama örneklerinin yakın zamanda Türkiye'de de görülmesi beklenmektedir.

\section{SONUÇ}

Girişimciler projelerini veya girişimlerini finanse etmek için ihtiyaç duydukları fonu ailelerinden ve/veya yakın çevrelerinden, banka gibi geleneksel kredi kurumlarından, melek yatırımcılardan veya girişim sermayesi yatırım fonları/ortaklıklarından elde edebilirler. Bunların dışında, girişimciler başka finansman yöntemlerini kullanarak da borç ve/veya

\footnotetext{
${ }^{2}$ Belirli koşulları sağlayan (nakit ve finansal varlıklarının toplamı en az 1 milyon TL olmak gibi) ve talebe dayalı olarak profesyonel müşteri olarak kabul edilen bireyler ile bireysel katılım yatırımcısı (melek yatırımcı) lisansına sahip bireyler, nitelikli yatırımcı olarak kabul edilmektedirler.
} 
özkaynak şeklinde fon sağlayabilirler. Girişimcilerin kullanabileceği her bir yöntemin kendine özgü üstünlükleri ve sakıncaları olduğu gibi, söz konusu yöntemlerin kullanılabileceği durum ve şartlar da farklılıklar gösterebilmektedir.

Kitlesel fonlama, girişimcinin finansmanında yeni ve alternatif bir finansman yöntemi olarak 2000'li yıllarda ortaya çıkmıştır. Öncelikle, ABD, İngiltere ve Avrupa'da gelişen bu finansman yöntemi hızla diğer ülkelere de yayılmıştır. Kitlesel fonlama piyasasındaki oyuncuların (fon arayanlar, fon sağlayanlar ve platformlar) sayısının ve buna bağlı olarak yıllık işlem hacminin hızla artması, düzenleyici kurumların da dikkatini çekmiş ve birçok ülke kitlesel fonlamanın en azından belirli türlerine ilişkin yasal düzenlemeler yapmaya başlamıştır. Kitlesel fonlamanın yasal bir zemine oturtulmaya çalışılması, tarafların maruz kalabileceği olası risklerin azaltılması, güvenin sağlanması ve piyasanın gelişmeye devam etmesi açısından oldukça önemlidir. Türkiye'de de 2011 yılında başlayan kitlesel fonlamaya ilişkin ilk yasal düzenleme 2017 yılında, ikincil düzenleme ise 2019 y1lında, sadece pay bazlı kitlesel fonlamaya ilişkin yapılmıştır. Böylece mevcut durumda uygulanan bağış ve ödül bazlı kitlesel fonlamaya ilave olarak, pay bazlı kitlesel fonlama uygulamasının da önü açılmıştır. $\mathrm{Bu}$ önemli bir gelişmedir. Çünkü ödül bazlı kitlesel fonlamada, girişimciler spesifik projeleri için sınırlı tutarda fon toplayabilme imkanına sahip iken, pay bazlı kitlesel fonlamada kitlelere pay satarak finansman ihtiyaçlarının önemli bir kısmını karşılayabilirler. Projesine veya işletmesine melek yatırımcı ya da girişim sermayesi ortaklığı/fonu bulamayan girişimciler, pay karşılığında halktan para talep edebilirler. Küçük yatırımcılar da, aynen melek yatırımcılar gibi, gelecek vaat eden projelere veya girişimlere ortak olabilirler. Kitlesel fonlamanın gelişmesinde, genel olarak yasal bir çerçevenin oluşturulmuş olması, internet ve sosyal medya kullanımının yaygın olması gibi faktörler önemli olmakla birlikte, girişimcilik kültürü de oldukça önemlidir. Kitlesel fonlama yöntemi, girişimcilik kültürünün bir yansıması olarak hem yeni girişimcilerin ortaya çıkmasını hem de bu girişimcilerin desteklenmesini kolaylaştırmaktadır. Bu nedenle, girişimcilik ve girişimcinin finansmanı açısından kitlesel fonlama piyasasının büyümesi ve gelişmesi önem teşkil etmektedir.

\section{KAYNAKLAR}

Açıkgöz, Betül - Ayanoglu, Yıldız - Yanık, Serap S. (2020), "Muhasebe Bakış Açısından Bağış (Yardım) ve Ödüle Dayalı Kitlesel Fonlama", Muhasebe ve Finansman Dergisi, (86), ss. 57-78.

Agrawal, Ajay - Catalini, Christian - Goldfarb, Avi (2014), "Some Simple Economics of Crowdfunding”, In: Innovation Policy and the Economy, Volume 14, Lerner and Stern pp. 63 - 97.

Ania, Asier ve Charlesworth, Christopher (2015), "Crowdfunding Guide For Nonprofits, Charities and Social Impact Projects”, Centre for Social Innovation, HiveWire Inc.

Atsan, Nuray - Oruç Erdoğan, Eda (2015), "Girişimciler İçin Alternatif Bir Finansman Yöntemi:7Kitlesel Fonlama (Crowdfunding)”, Eskişehir Osmangazi Üniversitesi İİBF Dergisi, 10(1), ss. 297-32.

Baltacı, Ali (2019), "Nitel Araştırma Süreci: Nitel Bir Araştırma Nasıl Yapılır?”, Ahi Evran Üniversitesi Sosyal Bilimler Enstitüsü Dergisi (AEÜSBED), 5(2), ss.368-388. 
Beaulieu, Tanya Y. - Sarker, Suprateek - Sarker, Saonee (2015), “A Conceptual Framework for Understanding Crowdfunding", Communications of the Association for Information Systems, 37, pp. 1-31.

Beier, Michael - Wagner, Kerstin (2016), "User Behavior in Crowdfunding Platforms: Exploratory Evidence from Switzerland”, 2016 49th Hawaii International Conference on System Sciences.

Belleflamme, Paul - Lambert, Thomas - Schwienbacher, Armin (2010), “Crowdfunding: An Industrial Organization Perspective", The workshop of "Digital Business Models: Understanding Strategies", Paris, June 25-26.

Bijkerk, Werner (2014), "Risks and Benefits of Crowd-funding”, AMCC Training Seminar, Tokyo.

CFIA, (2020). Australian Crowdfunding Platforms. https://www.cfinstitute.org/platforms.html (Erişim Tarihi: 14.03.2020)

Chervyakov, Dmitry - Rocholl, Jörg (2019), "How to Make Crowdfunding Work in Europe”, Policy Contribution, Issue no 6.

Cumming, Douglas J. - Leboeuf, Gaël - Schwienbacher, Armin (2020), "Crowdfunding Models: Keep-It-All vs. All-Or-Nothing”, Financial Management, 49, pp. 331-360.

Çubukçu, Ceren (2017), "Kitlesel Fonlama: Türkiye'deki Kitlesel Fonlama Platformları Üzerinden Bir Değerlendirme”, Girişimcilik ve İnovasyon Yönetimi Dergisi, 6(2), ss. 155-172.

Daştan, İkram - Gürler, Cem (2018), “Online Finansman Yöntemi Olarak Kitlesel Fonlama: Planlanmış Davranış Teorisinin Analizi”, Yalova Sosyal Bilimler Dergisi, 8(17), ss. 169-186.

Dikaputra, Rinaldo - Sulung, Liyu Adhi Kasari - Kot, Sebastian (2019), “Analysis of Success Factors of Reward-Based Crowdfunding Campaigns Using Multi-Theory Approach in ASEAN-5 Countries”, Social Sciences, 8(10), pp. 1-15.

Fettahoğlu, Sibel - Khusayan, Saulye (2017), "Yeni Finansman Olanağı: Kitle Fonlama", Uşak Üniversitesi Sosyal Bilimler Dergisi, 10(4), ss. 497-521

Freedman, David M. - Nutting, Matthew R. (2015), "A Brief History of Crowdfunding: Including Rewards, Donation, Debt, and Equity Platforms in the USA", http://www.freedman-chicago.com/ec4i/History-of-Crowdfunding.pdf (Erişim Tarihi: 10.05.2020).

Holtland, Hester - van Heck, Vicky (2019), “Institutional Investors \& Crowdfunding: The Right Match?”, Whitepaper, VBDO.

https://www.crowdfon.com/hakkimizda (Erişim Tarihi: 24.05.2020) 
https://www.gofundme.com/c/about-us (Erişim Tarihi: 25.05.2020).

Huang, Zaiyu - Chiu, Candy Lim - Mo, Sha - Marjerison, Rob (2018), "The Nature of Crowdfunding in China: Initial Evidence”, Asia Pacific Journal of Innovation and Entrepreneurship, 12(3), pp. 300-322.

Işık, Demet (2013). "Üniversite Kütüphanelerinde Web 2.0 Teknolojilerinin Kullanımı ve Web Tabanlı Kullanıcı Eğitimi İçin Öneriler”, Türk Kütüphaneciliği, 27(1), 100-116.

infoDev (Information for Development Program), (2013). Crowdfunding's Potential for the Developing World. Washington, DC: World Bank.

Kirby, Eleanor - Worner, Shane (2014), “Crowd-funding: An Infant Industry Growing Fast”, Staff Working Paper of the IOSCO Research Department.

Kitlesel Fonlama Derneği, (2017), “Kitlesel Fonlama: Kanun Tasarısı ve İkincil Düzenleme Üzerine Görüş ve Tavsiyeler”, Çalıştay Raporu.

Kunz, Michael Marcin - Englisch, Oliver - Beck, Jan - Bretschneider, Ulrich (2016), "Sometimes You Win, Sometimes You Learn - Success Factors in Reward-Based Crowdfunding”, In: Multikonferenz Wirtschaftsinformatik (MKWI), Ilmenau, pp.467478.

Mollick, Ethan (2014). The Dynamics of Crowdfunding: An Exploratory Study”, Journal of Business Venturing, 29, pp. 1-16.

Möllenkamp, Nilas (2017), “Determinants of Loan Performance in P2P Lending”, 9th IBA Bachelor Thesis Conference, July 5th, Enschede, The Netherlands.

Nesta, (2012), “An Introduction to Crowdfunding”, https://www.ema.eu/fileadmin/content/REALISE_IT_2/REALISE_IT_3/IntroToCrowdfunding.pdf (Erişim Tarihi: 10.05.2020)

Onur, Mediha Nur - Değirmenci, Öznur (2015), “Crowdfunding - Kitle Fonlaması”, T.C. Başbakanlık Hazine Müsteşarlığı Çalışma Raporları, Sayı: 2015-7.

P2PMarketData, (16.05.2020). https://p2pmarketdata.com/crowdfunding-statisticsworldwide/ (Erişim Tarihi: 24.05.2020).

Paakkarinen, Pilvi (2016), "Success Factors in Reward based and Equity based Crowdfunding in Finland”, Aalto University School of Business Master's Thesis.

Pierrakis, Yannis (2019). "Peer-to-Peer Lending to Businesses: Investors' Characteristics, Investment Criteria and Motivation”, The International Journal of Entrepreneurship and Innovation, 20(4), pp.239-250.

Polena, Michal - Regner, Tobias (2016), “Determinants of Borrowers' Default in P2P Lending Under Consideration of The Loan Risk Class", Jena Economic Research Papers, No. 2016-023, Friedrich Schiller University Jena. 
Röthler, David - Wenzlaff, Karsten (2011), “Crowdfunding Schemes in Europe”, EENC Report.

Sakızlı, Emre (2018), Alternatif Bir Finansman Yöntemi: Kitlesel Fonlama, İktisadi Kalkınma Vakfı Yayını, İstanbul.

Sara, Bannerman (2012), “Crowfunding Culture”, Wi: Journal of Mobile Culture, 6(4), pp. 123.

Sermaye Piyasası Kurulu (SPK), Paya Dayalı Kitle Fonlaması Tebliği (III-35/A.1).

Song, Yang - van Boeschoten, Robert (2015), "Success factors for Crowdfunding Founders and Funders", Proceedings of the 5th International Conference on Collaborative Innovation Networks COINs15, Tokyo, Japan March 12-14.

StartUp, (14 Şubat 2015), "Savaş Ünsal: Fikri olan gençlere ilk desteği veriyorum”, Söyleşi, https://startup.capital.com.tr/soylesi/savas-unsal-fikri-olan-genclere-ilk-destegiveriyorum.html (Erişim Tarihi: 22.05.2020)

Vural, Aslı - Doğan, Deniz Umut (2019), "Girişimcilik Finansmanında Yeni Bir Model: Kitle Fonlaması", İşletme Araştırmaları Dergisi, 11(1), ss. 88-100.

Wash, Rick - Solomon, Jacob (2014), "Coordinating Donors on Crowdfunding Websites", CSCW 2014: Crowdfunding: "Show me the Money!", February 15-19, Baltimore, MD, USA.

Xiao, Zhao - Li, Yuelei - Zhang, Kang (2018), "Visual Analysis of Risks in Peer-to-Peer Lending Market”, Personal and Ubiquitous Computing, 22, pp. 825-838.

Zvilichovsky, David - Inbar, Yael - Barzilay, Ohad (2015), "Playing Both Sides of The Market: Success and Reciprocity on Crowdfunding Platforms", Available at SSRN: https://ssrn.com/abstract=2304101 (Erişim Tarihi: 08.05.2020). 